\title{
1 \\ Popular Music, Stars and Stardom: Definitions, Discourses, Interpretations
}

\section{Stephen Loy, Julie Rickwood and Samantha Bennett}

What do we mean when we talk of 'pop stars' or 'rock stars'? What do we seek to convey when we describe a particular performer as a 'pop star'? The use of the term 'star' to describe an individual's outstanding achievement within a particular field may be traced as far back as the early nineteenth century, when the term was used in popular discourse concerning those who excelled in their fields, particularly in the theatre and the sporting arena (Oxford English Dictionary Online, 2016). The term gained a particular currency, however, with its use in describing the most prominent and popular actors of the Hollywood film studios during the first half of the twentieth century. In this sense, the application of the word star connotes publicly recognised success, and it is often in this manner that we apply the terms 'pop star' or 'rock star' to acclaimed performers of popular music.

However, our identification and veneration of stars, either of stage or screen, is demonstrative of a complex web of social and cultural processes, which raises other questions, and invites comparisons with notions of fame and celebrity. In particular, the way a star's persona may be understood as both commercial commodity and an individualised, personalised reflection of broader social or cultural meanings, invites questions of the 
ways in which the star becomes 'an object of cultural politics' (Gledhill, 1991, p. xiv). Here, notions of stardom intersect and overlap with those of celebrity.

Whereas stardom is taken to derive from professional success and its popular recognition, celebrity as a form of fame is more contested, particularly in terms of its perceived value. Fred Inglis, in his A Short History of Celebrity, makes a historical distinction between renown, which is governed by and attributed to individuals based on position or achievement, and the more recent phenomenon of celebrity, which he argues is more transitory (Inglis, 2010, pp. 4-5). This sense that celebrity may be disconnected from professional success in a field is further emphasised by Graeme Turner, who argues that 'the modern celebrity may claim no special achievements other than the attraction of public attention' (Turner, 2014, p. 3). Similarly, Sean Redmond and Su Holmes note the at times derogatory connotations of the term 'celebrity', which places it in a hierarchical relationship with the notion of 'stardom': 'the concept of the "star" [is] positioned above the concept of the celebrity - with its persistent association with fame as more ubiquitous, and thus devalued, currency' (Redmond and Holmes, 2007, p. 8).

While the term 'star' continues to be used to describe 'those known for a public role in a particular profession' (Redmond and Holmes, 2007, p. 9), and, therefore, may be distinguished from the notion of celebrity as one who is 'well-known for their well-knownness' (Boorstin, 1971, p. 58), Marsha Orgeron has noted the 'categorical slipperiness' between these terms, and others such as 'personality' and 'superstar', with meanings shifting in response to developments in culture and its depiction (Orgeron, 2008, 190). Despite these particulars of definition, the role that stars play in the pervasive cultural, commercial and social processes connected with popular culture mandates a consideration of the phenomenon in the context of these broader issues. Indeed, the development of academic disciplines around stardom and celebrity reflects the diversity of approaches that may be taken to its investigation.

Critical discourses concerning stardom and celebrity date from the 1970s, arising initially as a component of the emergent film studies of the period. It was in examinations of the roles played by stars within the film industry, and their significance to audiences, that the field has its genesis. In particular, Richard Dyer's book Stars, first published in 1979, proved a seminal work in the establishment of approaches to issues of stardom as 
they related to the commercial and social processes of the film industry. Dyer's was the first critical study of stardom in cinema that sought to interrogate how stars, as images projected within film and via other 'media texts' and intersecting with their functional role as characters within films, through both their on-screen characters and off-screen personae, informed and helped shape social and cultural ideas (Dyer, 1998, p. 1). Dyer's critique of the 'star image' (Dyer, 1998, p. 129) and its role in the creation of sociocultural meaning was further developed in his subsequent work Heavenly Bodies: Film Stars and Society, in which he focused on the significant figures of Marilyn Monroe, Paul Robeson and Judy Garland to explore the interrelationship of star construction and audience reception in the creation of cultural meaning (Dyer, 2004).

Dyer's approach to the critique of stardom through the notion of the 'star image' as a 'media text' set a critical frame for the exploration of the social function of stardom within the entertainment industries, influencing many subsequent studies. While acknowledging this debt, and firmly grounded in the discipline of film studies, Christine Gledhill's 1991 collection, Stardom: Industry of Desire, brought together studies by a range of contributors from across the disciplines of cultural studies, media and communication studies, gender studies and politics, emphasising a belief in the study of stardom as necessarily interdisciplinary. Gledhill (1991) writes in the introduction to the collection:

The star challenges analysis in the way it crosses boundaries: a product of mass culture, but retaining theatrical concerns with acting, performance and art; an industrial marketing device, but a signifying element in films; a social sign, carrying cultural meanings and ideological values, which expresses the intimacies of individual personality, inviting desire and identification; an emblem of national celebrity, founded on the body, fashion and personal style; a product of capitalism and the ideology of individualism, yet a site of contest by marginalised groups; a figure consumed for his or her personal life, who competes for allegiance with statesmen and politicians. (p. xiii)

This eloquent outline of the complex issues at play in stardom's social and cultural functioning reflects the ways in which discourses in studies of stardom and celebrity have subsequently developed, with a burgeoning of the field into a broad range of disciplines, particularly since the turn of the millennium. 
Orgeron identifies three critical theoretical directions, which encompass much of the subsequent interdisciplinary diversity of the work conducted within stardom studies during the past two decades. Noting that 'the scholarship about media celebrity is diffuse in terms of both its breadth and its disciplinary focus', Orgeron identifies the key fields as 'the work of stardom', approaches that further develop Dyer's notion of the 'star text', and studies that examine the role of stars within issues of 'identity politics' (Orgeron 2008, pp. 201-202).

The 'work of stardom', as described by Orgeron, extends far beyond the labour of that which is required of the star in the production of a film or other creative artefact. Indeed, 'movie stars are actors well beyond the limited time they spend in front of the cameras', and the requirement that the star continue the presentation of a public persona extends far beyond their formal acting work (Orgeron, 2008, p. 202). Despite this being a key element of the perpetuation of stardom, Orgeron argues that it is an aspect of the field that is rarely examined, with a preference for the consideration of stars as celebrity icons taking precedence. Despite this, in recent decades analyses of the labour processes that go into the production and support of the star image have further developed this area of stardom studies. The work of Graeme Turner, in particular his Understanding Celebrity (2014) and, with Frances Bonner and P. David Marshall, Fame Games (2000), interrogates the elements of the celebrity industries that create and support the projection of stars and celebrities, uncovering aspects of these industries that 'actively mask their own activities' (Turner, 2014, p. 44).

Studies that develop Dyer's 'media text' approach focus on the industry construction of stars, and how the images and personae created are employed to influence audience consumption and reception. 'The construction and consumption of star promotion are necessarily distinct categories, each revealing more, perhaps, about their maker and consumer than about the stars themselves' (Orgeron, 2008, pp. 205206). Therefore, studies in this vein combine aspects of the fields of economics, media and communication studies with sociological studies of audience behaviour and reception. An example of the development of stardom studies from this perspective is the work of Christine Geraghty. In 'Re-examining Stardom: Questions of Texts, Bodies and Performance' (2000), Geraghty further develops the study of star images through 
the interrogation of the ways in which stars create cultural meaning, examining distinctions between these processes when considering the star as a celebrity as opposed to a professional and a performer.

The interdisciplinary nature of stardom studies is further demonstrated by those studies that investigate issues of what Orgeron describes as 'identity politics'. Orgeron characterises these works as focusing on the 'human' aspects of stardom, in contrast to those that focus on the industrial mechanisms of stardom (Orgeron, 2008, p. 209). The multiplicity of these studies concerning issues of gender, race, ethnicity, sexuality and politics as they intersect with stardom and celebrity may be observed in the range of articles published in the first six years of the journal Celebrity Studies, which published its inaugural issue in 2010: Sean Redmond's 'Avatar Obama in the Age of Liquid Celebrity' (2010), Anita Brady's “"This is Why Mainstream America Votes Against Gays, Adam Lambert": Contemporary Outness and Gay Celebrity' (2011), Deborah Jermyn's “"Get a Life, Ladies. Your Old One is Not Coming Back": Ageing, Ageism and the Lifespan of Female Celebrity' (2012), and Ruth A. Deller's 'Star Image, Celebrity Reality Television and the Fame Cycle' (2016). These studies, and indeed the journal itself, not only serve to exemplify the increasingly interdisciplinary nature of the field, but also the continued broadening of the field to encompass stardom as manifested in the film industry, and questions of stardom and celebrity as perpetuated through other media including television and, more recently, social media.

Within this burgeoning interest in the study of stardom and celebrity in the second half of the twentieth century and the first decades of the twenty-first century, another significant approach has been to investigate the history of ideas of stardom and celebrity prior to the development of mass market entertainment industries in the twentieth century. These studies provide a broader historical contextual positioning of the study of stardom and celebrity. Inglis, in his A Short History of Celebrity, aligns the development of the social processes of fame, celebrity and stardom with the acceleration of the development of modernity from the mid-eighteenth century. 'The business of renown and celebrity has been in the making for two and a half centuries. It was not thought up by the hellhounds of publicity a decade ago' (Inglis, 2010, p. 3). Historical studies such as Inglis' provide a greater context for the theorising of stardom that had originally assumed a focus on the stars of the film industry alone. 
Despite its origins within film studies in the second half of the twentieth century, the broadening of the study of the processes of stardom and celebrity, and the increasingly interdisciplinary nature of these studies, have also observed an increase in the analysis of the role of stardom within the production and reception of popular music. In considering issues of stardom within the popular music industry, many of the same questions of star construction and reception apply, though particulars of the mechanics of the music industry necessarily shape perspectives on these issues. Similarly, many questions of identity as negotiated through processes of stardom remain current when examining the reception of the stars of popular music.

Identifying the point at which stardom became a key aspect of the popular music industry is difficult. However, as a star whose public persona drew on his professional activities as both a popular musician and screen actor during the 1940s and 1950s, Frank Sinatra's stardom was not only an early example of stardom within the postwar US popular music industry, but also an example of the potential overlap in the nature of stardom within both the film and music industries. Karen McNally argues that, while 'Sinatra is best known and most respected as a singer', the intertextual nature of Sinatra's star image derives from the combination of his renown as a musician and his presentation of character within films. 'Sinatra's film identity began as this overt combination of character and star image-an image that predates cinematic connections, reinforcing the importance of extrafilmic image construction' (McNally, 2008, p. 7). Sinatra's multifaceted career highlights the potential for stardom within the popular music industry to be augmented through other professional activities.

The emergence of rock-and-roll in the 1950s and the prominence of artists such as Chuck Berry and Elvis Presley have been identified by David R. Shumway as signifying the emergence of a rock stardom, arguing 'there was no rock and roll before there were rock stars' (2007, p. 530). Shumway further says 'the full-blown phenomenon of rock stardom did not develop until the Beatles and Rolling Stones were able to use Elvis' example as a conception of a career path' (p. 530). This is corroborated by other historical accounts and studies of star production, such as Martin Cloonan's 'The Production of English Rock and Roll Stardom in the 1950s' (2009) and Ian Inglis' 'Ideology, Trajectory and Stardom: Elvis Presley and the Beatles' (1996). 
Successful rock-and-roll artists of the 1950s and 1960s set a precedent for the reception of stars in the later twentieth century. Michael Jackson exemplifies this, reaching the pinnacle of popular music stardom, first as a child star in the 1970s with Motown's The Jackson Five and later as a solo pop artist. Jacqueline Warwick (2012) identified his 'massive appeal, historical significance, celebrity status and artistic accomplishments' (p. 241) as elements of his stardom and cited 'discomfort with his career as a child star' (p. 242) as affecting the surprising lack of critical and scholarly attention. Interestingly, this understanding of stardom rejects the economic component of relative commercial success, instead focusing on artistic achievement.

Yet, monetary success is one significant way in which music stardom is commonly measured. In a key work on the economics of stars in the areas of sport and the arts, Moshe Adler (2006, p. 897) interpreted 'super stars' as those having 'considerable prominence and success in their field and whose earnings as a result are significantly greater than the earnings of their competitors'. Adler argues that 'super stardom' is not commensurate with talent, as has been previously argued by Sherwin Rosen (1981). Rather, stardom is attributable to consumers and their need to consume the same art as others to acquire 'consumption capital':

Appreciation increases with knowledge. But how does one know about music? By listening to it, and by discussing it with other persons who know about it. In this learning process lies the key to the phenomenon of stars. (Adler, 1985, p. 208)

Viewed in this way, stardom may be construed as a measurement of popularity by quantity of consumers, in both the acquisition of recordings and concert attendance, and is not necessarily an indicator of musical ability or talent.

Personal identification with stars on the part of the consumer is a significant aspect of the process of star consumption and reception. In popular music, this process is mediated by the music and the meanings consumers interpret in the music. Often, consumers attempt to interpret the music and lyrics of a star persona by looking for connections between the music and details of the personal lives of the individual artist and themselves. Thus, the meaning received works in conjunction with an individual's identification with a star's publicly presented persona to strengthen the perceived connection between the consumer and the star. Through an analysis of print biographies of popular musicians, 
Toynbee (2000) noted an assumption that the meaning of the music could be found in the lives of its makers. His argument is that 'musicians are exemplary agents who make a difference, in the shape of different songs, sounds and styles' (2000, p. x). The music, in this context, is primary; its production 'carries the promise of transcendence of the ordinary' (2000, p. x), and functions as a banner under which ordinary people can create community, with the musicians as 'representatives mandated by "their" people' (2000, p. x). Meaning, then, is the subject of negotiation between the producers and audience.

Similarly, Roy Shuker (2012) has discussed stardom in popular music as a consequence of the interaction between artistic creativity and audience reception:

Stardom in popular music, as in other forms of popular culture, is as much about illusion and appeal to the fantasies of the audience, as it is about talent and creativity. Stars function as mythic constructs, playing a key role in their fans ability to construct meaning out of everyday life. Such stars must also be seen as economic entities, a unique commodity form which is both a labour process and product, effectively brands who mobilize audiences and promote the products of the music industry. (pp. 318-319).

Shuker (2012, p. 319) argues that the study of stardom in popular music has been limited and has generally produced a discourse that revealed 'how stardom has become a construct with a number of dimensions: the economic, the cultural and the aesthetic or creative'. Importantly, Shuker argues that fascination with the stars of popular music cannot be simply explained in terms of the political economy. Values such as authenticity, which are invested in individual musicians, create and maintain the notion of the star through the fanatic ritual of adoration and transcendence. Many contemporary stars are now frequently considered auteurs, carefully maintaining control over their public profile. Recent developments in the field of celebrity studies have involved a redefinition of the public/private boundary with an emphasis on the private life rather than the career becoming prominent (Shuker, 2012, p. 320).

While there might be many biographies of, or extensive literature on, a popular musician or band written by both journalists and academics, Shuker is one of only a handful of scholars who have considered the connections between popular music, stars and stardom more broadly. The interrelationship of ritual, pleasure and economics in popular music 
continues to create audiences, he declares, fuelling 'individual fantasy ... and [the creation of] musical icons and cultural myths' (2016, p. vii). The musical icons, the stars, cultural myths and the stardom are inherent in popular music and vital to its existence.

Shuker's recent edition of Understanding Popular Music Culture devotes a chapter to auteurs and stars (2016, pp. 59-80) and draws on more recent examples of artists as stars than those used in the previous editions, including Lady Gaga, Taylor Swift and Lorde. As in earlier editions, Shuker's chapter continues to rely on highlighting individual career profiles that illustrate 'the interaction of musical authorship with genres, the music industry, fans and audiences, and history' (2016, p. 7), although displaying a shift to equal gender and more contemporary representation. There is a fine distinction between popular music stardom and auteur status; the latter signifying the reception of an artist as being genuinely creative, and one who explores and extends the dimensions of their art form. The attribution of auteur status to an artist rests on 'necessarily ambiguous' (Holmes, 2004, p. 154) notions of authenticity, while stars 'function as mythic constructs' that operate beyond the production of a substantial body of work, and reinterpret or reaffirm popular music styles and genres.

This authenticity discourse concerns the significance of popular musicians received by their audiences as 'authentic', bringing questions of star construction into sharper relief. Issues of auteurship, performance and the presentation of the self have long driven discussions, among fans and critics alike, regarding what distinguishes those considered 'authentic' artists from those perceived as industry constructions. ${ }^{1}$ The attribution of star status is often reserved within discourses on popular music for artists considered to fulfil one or more of the criteria of authenticity as a popular music artist. P. David Marshall's chapter, 'The Meanings of the Popular Music Celebrity: The Construction of Distinctive Authenticity', part of his larger study Celebrity and Power: Fame in Contemporary Culture (1997), examines these issues in relation to the operation of stardom within the popular music industry. This intersection between pop/rock stardom and attributions of authenticity highlights connections between the star status achieved by artists and canon formation in rock and pop music.

1 For further discussion of debates concerning authenticity in popular music studies, see Allan F. Moore (2002) and Keir Keightley (2001). 
From the expansion of the record industry simultaneous to the advent of rock-and-roll, numerous popular musicians have been assimilated into a rock/pop canon, similar in construction to canons of repertoire and composers in Western art music. ${ }^{2}$ Since the establishment of the rock canon, many African-American jazz and blues musicians have been admitted, in belated recognition of contribution of these artists to the musical and aesthetic foundation of rock and pop music. Stardom, in conjunction with endurance, is one factor that informs canonisation. The ability for the work of a popular music artist to be strongly received not simply at the time, but over time, is integral to its potential canonisation. However, as Carys Wyn Jones noted, the construction of a rock canon involves many records and artists widely received as non-rock music. Wyn Jones argues that some records are assimilated into the rock canon not necessarily because they are rock albums, but because they display rock values, 'albeit ones inherited from the high arts' (2008, p. 2). Cleveland's Rock \& Roll Hall of Fame and Museum ${ }^{3}$ is a good example of the ascription of rock values to artists and works of other genres. Inductees include rap stars Tupac Shakur and NWA, pop stars ABBA and the Bee Gees, and funk stars Sly and the Family Stone and Funkadelic. Inductions also include affiliates of rock performance such as electric guitar pioneers Leo Fender and Les Paul, and producers including Leonard Chess, Glyn Johns and Quincy Jones, suggesting that some associates and affiliates of canonised rock artists are received as equally important as the stars themselves.

Another significant aspect of the role of stardom in the process of canon formation is the posthumous canonisation of popular music artists. That the posthumous attainment of canonical status is more often attributed to stars of rock and hip-hop than those of pop music aligns with the critical reception of rock and hip-hop as valorising auteurship over the performance of the works of others. It is unsurprising, then, that the star status of such artists becomes heightened upon their death. More recently, as Catherine Strong and Barbara Lebrun noted in Death and the Rock Star (2015), there is a growing fascination with the ramifications of death in popular music, in terms of both commercial potential and reception. The authors themselves admit to a shared fascination with popular music

2 For a discussion on canon formation in Western art music, see Lydia Goehr (2007).

3 See rockhall.com/inductees for a full list of Rock \& Roll Hall of Fame and Museum inductees. 
stars that have committed suicide (Strong and Lebrun, 2015, p. 1). This is an innovative and insightful exploration of death in popular music, covering the gamut of popular music's most renowned deaths.

Indeed, the death of a star, or a declining star career, is often discussed using 'falling' or 'fallen' star metaphors. For example, the careers of former rock stars Gary Glitter and Ian Watkins, and pop star Gloria Trevi, all ended as a consequence of their convictions for serious crimes. In each of these cases, journalists routinely used 'fallen star' narratives to refer to the immediate drop in the cultural status of these artists, the inevitable result of such crimes. ${ }^{4}$

Within discourses of popular music and rock stardom, and the processes of pop/rock canonisation, women are often the hidden stars. Pop/rock historiography is largely written by men. Therefore, documented histories, critiques and interpretations of contributions made by female and nonbinary identifying musicians to popular music are limited. Of note, then, is that in this edited collection, three biographical chapters that focus on women musicians are presented. In a counter narrative to the desire for stardom are Australian musicians Judy Jacques and Wendy Saddington, who shrugged off star status in the 1960s and 1970s to pursue creative paths independent of the popular music industry. While we now see a greater diversity of types of star and celebrity, 'whether with regard to TV, pop music, film, sport, or people working across different media forms' (Holmes, 2004, p. 151), a feminist critique will readily highlight that a male bias within the cultural industries continues. Conversely, Beyoncé has taken control of the 'holistic world' across her music, videos, concerts and media presence (Macrossan, Chapter 8). She has successfully constructed, managed and facilitated her connection with her audience through the production of musical outputs perceived to be unique and significant within the current congested popular music landscape. This suggests that the immediacy and global capture of contemporary technology and social media provide greater opportunities for popular musicians to establish an audience base and then to operate more independently of the major industry players.

4 In 2008, Reuters reported on Glitter's conviction for molestation. The article of 14 August began 'Fallen British rock star Gary Glitter ...' (Binh, 2008). In December 2013, shortly after Lost Prophets lead singer Ian Watkins was convicted of multiple child sex offences, newspaper Wales Online published an article referring to Watkins as a 'fallen rock star'. In 2002, The Sydney Morning Herald journalist Richard Boudreaux referred to Gloria Trevi as a 'fallen rock star' following her return to Mexico from Brazil after being convicted of child sex offences. 
The late twentieth century has witnessed the rise of music technology stars, in terms of designers, engineers and equipment. In Sound City, for example, Foo Fighters guitarist and documentary director Dave Grohl (2013) foregrounded the recording studio's Neve 8078 console and its designer, British electronics engineer Rupert Neve, as the 'stars' of the documentary, equal in status to the studio's recording artists and canonical recordings. This notion of what Bennett has called 'technological iconicity' (2012) is increasingly visible in discourses of technological stardom. Consider, for example, this definition of masterclasses for the 2017 convention of the Audio Engineering Society (AES, 2017):

An AES Master Class is given by an expert recognized in the field; a wellknown star with name recognition. There is one presenter per session. An example would be having Rupert Neve talk about console design; or Mr Marshall talk about guitar amplifier design. This can be thought of as a star discussing something that was famous, or a high-level tutorial, covering advanced applications. We hope to draw people into the convention to hear a star. ${ }^{5}$

The canonisation of popular music stars has, therefore, clearly extended far beyond artist, genre and recording.

Today, the notion of popular music stardom is manifested in its most instant, gratifying and exaggerated form in the television reality program. Su Holmes (2004, p. 147) recognised the ways in which programs including Popstars and Pop Idol 'place the entire notion of stardom at center stage'. Reality television shows, including The Voice, X Factor and programs based on other similar formats, project an aspirational notion of stardom as manufactured, potentially transformative and instantaneous. Central to these shows are the music industry power intermediaries, in some cases in conjunction with the voting public, who decide which of the performers project the necessary star aura, narrowing the competition until an eventual winner is selected. Unsurprisingly, many tensions exist surrounding these formats. The emphasis on singing and performing cover versions of well-known contemporary songs obscures understandings of stardom based on notions of auteurship and originality. Since the consolidation of rock stardom in the 1960s, perceptions of musicality and originality have been central to the attribution of auteur status to popular musicians and, therefore, to the shaping of rock and stars in the

5 See the proposal submission page of the Audio Engineering Society website: aes.org/events/ session_proposals/ (page discontinued, accessed April 2017). 
commercial music industry. Thus, overshadowing of these values within projections of popular music stardom presented in these reality television programs is often treated with suspicion. The manufactured aspect of 'overnight success' that such television shows convey also contradicts notions of the endurance of reception so intrinsic to pop/rock canonical values. Yet, these shows successfully achieve the mediation of the aesthetics of stardom via live performance and the pressures commensurate with performance to large audiences. To reveal these somewhat intangible aesthetics of stardom, Mark Duffett (2009) has explored the aura elicited by musicians in live performance. He noted an intangible 'symbolic economy' of cultural power surrounding the star and recognised how fans who "talk about live concerts and meetings with stars adopt terms like "power", "energy," and "electricity" as their currency of discussion' (p. 41). Critically, he noted heckling by audience members as a symbolic gesture that not only shifts the power balance between performers and fans, but also disrupts the aura of stardom emanating from the stage. This significant interpretation of stardom underlines the importance of the intangible in the star construct-canonisation, economic and commercial success and/or talent do not of themselves make a star.

Therefore, in popular music studies, we see the notions of stars, stardom and celebrity manifest in myriad ways. While we do not seek to investigate all potential lines of inquiry within this collection, nor discuss all artists considered stars of popular music, the studies brought together in this volume illuminate some interesting perspectives that serve to contribute to the developing discourse on stardom in popular music. When first discussing a theme for the 2015 Conference of the Australia and New Zealand branch of the International Association for the Study of Popular Music (IASPM), a focus on stars and stardom within popular music emerged after it was realised that, surprisingly, such an investigation had not been previously attempted in either a regional or an international conference of IASPM. Stars and stardom, it seemed, were so intertwined with contemporary popular music that their alignment had almost been taken for granted. The theme of 'Popular Music, Stars and Stardom' proved a fruitful field for exploration, with scholars addressing the theme and its related subjects from a variety of perspectives. Biographical appraisals were prevalent, and various applications of astronomical metaphors, in both cultural commentary and academic discourse, illuminated many inquiries. Others provided a critical discourse of stardom in the popular music industry more broadly. Collectively, the presentations demonstrated 
that popular music, stars and stardom were subjects ripe for investigation. The chapters that follow derive from papers that were first delivered at the conference, and serve to demonstrate that there remains scope for continued analysis of questions of stardom as they relate to popular music, its production and its reception.

The aims of this book, therefore, are threefold. First, in assembling a collection of chapters dedicated to the study of stars and stardom, we hope to bring together an overview of current discourse in this important, yet varied field. Second, we aim to expand on understandings of stardom via seven key works, each of which approaches the topics of stars and stardom in popular music from original angles. Third, we aim to reveal understandings of stardom by focusing on areas usually hidden in mainstream cultural commentary. This collection, therefore, explores stardom with emphasis on gender (in chapters by Robin Ryan, Julie Rickwood and Phoebe Macrossan), race (in chapters by John Whiteoak and Vincent Perry), the understudied areas of stardom in songwriting (in a chapter by Clive Harrison) and in the confluence of popular music and opera (in a chapter by Eve Klein).

In 'Interstellar songwriting: What Propels a Song Beyond Escape Velocity?', Clive Harrison uses a galactic metaphor to investigate creativity in the songwriting domain. Here, Mihaly Csikszentmihalyi's systems model of creativity (1988) is used as a framework to examine the ways songwriters negotiate their own creativity in the context of the field. Harrison posits the notion of the 'Pro-c' or professional songwriter and how factors affecting their songwriting practice have the potential to move them to 'Big-c' or paradigm-shifting creativity. Harrison recognises 'discriminant pattern recognition, naturalistic intelligence, productivity, fruitful asynchrony, propulsion theory, risk, field switching, expert variation and selective retention, and the production of significant works' as influencing the creative process of songwriting to varying degrees. In his findings, Harrison notes the confluence of 'exceptional choices based on "intuition"' and applications of 'dogged persistence, determination, focus, application' and other attributes as traits of a songwriter's expert status. This innovative chapter's galactic metaphors elucidate the construction of stardom within a songwriter's creative process.

John Whiteoak shifts the discussion of stars and stardom to the pre-jazz age in 'A Good Black Music Story? Black American Stars in Australian Musical Entertainment Before "Jazz". Here, Whiteoak critically 
negotiates the topic by first acknowledging the work of Ronald Radano in the construction of 'good' black music stories and the influence of both black and white sources that inform them. He goes on to recognise how 'numerous African-American singers, dancers and instrumentalists performed in Australia before Australia's Jazz Age' and in focusing on this era, illuminates the hidden stars that underpinned the emergence and development of Australian Jazz. In an insightful account of turn-of-thecentury Australian touring vaudeville, minstrelsy and early jazz, Whiteoak traces the impact of acts including Sheraden Corbyn's Original Georgia Minstrels, the Hicks-Sawyer Minstrels and Hugo's Colored Minstrels; the latter Whiteoak evaluates as ending 'a three-and-a-half-decade era in which African-American artists contributed directly to the shaping and content of popular music in Australia'. Finally, the contribution to Australian Jazz made by African-American star musicians is noted as a 'good black music story' deserved of its place in Australian music history.

This book makes a significant contribution to understandings of stars and stardom by revealing contributions made to popular music by understudied female artists. In 'You're Messin' Up My Mind: Why Judy Jacques Avoided the Path of the Pop Diva', Robin Ryan posits a case of 'stardom in flux' in the career of this overlooked Australian roots artist. In this critical biography, Ryan traces how Jacques negotiated a complex of stardoms during her career. First, Ryan recognises Jacques as a teenage jazz star and the formation of cult status surrounding her artistry. Moving into the 1960s, Ryan reveals Jacques' relationship with television and the commercial record industry and how her image adapted to the demands of mainstream media. Ryan notes the global reach of Jacques' stardom with the track 'You're Messin' Up My Mind' and its dissemination via Manchester's Northern Soul scene. The tension between Jacques' conformity to mainstream media stardom, and her own artistic integrity is discussed in insightful sections on free singing, autonomous and heritage stardom as Ryan concludes that Jacques' career was a negotiation between 'musical freedom and industry objectification'.

Providing another perspective on the Australian female artist and stardom, Julie Rickwood considers the legacy of the late underground rhythm-andblues artist Wendy Saddington. In a revealing account of Saddington's career, Rickwood contextualises the performer's work in 1970s Australian popular music before exploring the influence of African-American rhythmand-blues stars on Saddington's aesthetic. Posthumously, Saddington is posited as a pioneer, equal in artistic contribution to the Divinyls' Chrissy 
Amphlett. Rickwood evaluates Saddington's musical legacy, as well as her nonconformist identity in an illuminating account of a star otherwise hidden in Australian music historiography. Finally, Rickwood notes aspects of memory, heritage and commemoration among Saddington's fans, as manifested in the 2015 exhibition 'Underground Icon', held at Canberra Museum and Gallery. Rickwood concludes by noting how Saddington has been described as 'mercurial', her early career 'meteoric', her later performances occurring 'once in a blue moon' and her spiritual path into Krishna Consciousness 'transcendent', thus, articulating a cultural understanding of Wendy Saddington as an underground star.

Continuing the theme of revealing hidden stars, Vincent Perry's chapter focuses on the critical, yet rarely illuminated 'behind the scenes' musicianship of an important backing group. In 'Unsung Heroes: Recreating the Ensemble Dynamic of Motown's Funk Brothers', Perry considers the prolific and accomplished musicianship of the musicians of Berry Gordy's Motown backing band and seeks to highlight the prominence of their individual musical flair in the construction of Hitsville USA's iconic sound. Perry considers the concealed nature of recording artist backing bands in the 1960s and the tensions between musician anonymity relative to star performativity. In an exploration of creative practice, Perry's work then applies the ensemble dynamic of the Funk Brothers to his own recording project Soul Sundays. This account of practice-led research recreates the environmental, instrumental and aesthetic components of a Motown project and evaluates interpersonal skills, the limitations of historical recording processes and unified performance as major factors on its success.

In a chapter on the clashing of worlds of stardom, Eve Klein considers both the musical synergies and critical tensions in a record conflating two stars of entirely different musical spheres. 'When Divas and Rock Stars Collide: Interpreting Freddie Mercury and Montserrat Caballés Barcelona' posits Mercury's contribution as a natural extension of his fascination with opera. Klein first unpacks opera's location within popular culture: the presence of the operatic canon on record, the 'crossover' repertoire and operatic appropriations. She notes the consideration of the Mercury/Caballé duo as eccentric before analysing the similarities in musical style between Queen's 'Bohemian Rhapsody' and Mercury/Caballés 'Barcelona'. Here, Klein notes 'the aesthetic tendency underpinning both releases is operatic pastiche woven through rock with heavily mediated, hyper-real music production devices'. In conclusion, Klein considers 'Barcelona' in 
the contexts of both opera and rock and evaluates the record's difficult reception due to the ways it 'antagonises multiple authenticity gaps between operatic and rock performance styles'. Ultimately, Klein's article is a fascinating insight into the middlebrow; the collision of rock and opera stars is not necessarily a successful one.

In a fitting conclusion to this collection, Phoebe Macrossan shines a spotlight on one of today's biggest pop stars. In 'Intimacy, Authenticity and "Worlding" in Beyoncés Star Project', Macrossan interprets Beyoncés success as less a narrative of stardom and more a 'star project'. Here, she illustrates the construction of Beyoncés 'world' as one extending beyond visual imagery to incorporate both 'the active process of creating a world and the world itself'. Macrossan posits Beyoncés recent album Lemonade as an example of the star's 'worlding'; the music, imagery and political ideology along with an epic 60-minute film clip encapsulate this contemporary star's conceptual approach to artistic endeavour. Macrossan uses concepts adapted from film theory to scaffold her discussion of Beyoncés 'worlding' before using the critically acclaimed Lemonade as an example case study. Macrossan concludes that Beyoncés 'negotiation of stardom is now a strategy of constructing, maintaining and occupying Beyoncé World', also noting the active participatory role played by Beyoncés audience in the maintenance of her 'worlds'.

These chapters conceptualise the manifestation of stardom in popular music and in wider media. In doing so, they reveal hidden stars, illuminate fading stars, foreground shadowed stars and offer a breadth of analytical and contextual insight into this evolving discourse.

\section{References}

Adler, M. 1985. 'Stardom and Talent'. American Economic Review 75 (1): 208-212.

- 2006. 'Stardom and Talent'. In Handbook of the Economics of Art and Culture, edited by V. A. Ginsburg and D. Throsby, 895-906. Amsterdam: North-Holland.

Audio Engineering Society. 2017. 'AES Convention Proposals: Workshops, Tutorials, Master Classes, Game Audio etc.' aes.org/events/session_ proposals/ (page discontinued, accessed April 2017). 
Bennett, S. 2012. 'Endless Analogue: Situating Vintage Technologies in the Contemporary Recording \& Production Workplace'. Journal on the Art of Record Production 7.

Binh Minh, H. 2008. 'Vietnam to Free Gary Glitter This Month'. Reuters, 1 August. reuters.com/article/us-vietnam-glitter-idUSHAN 13338820080802 (accessed March 2017).

Boorstin, D. 1971. The Image: A Guide to Pseudo-Events in America. New York: Atheneum.

Boudreaux, R. 2002. 'Fallen Rock Star Flies Home to Face the Music in Sex Scandal'. Sydney Morning Herald, 23 December. smh.com.au/ articles/2002/12/22/1040510964491.html (accessed March 2017).

Brady, A. 2011. “"This is Why Mainstream America Votes Against Gays, Adam Lambert": Contemporary Outness and Gay Celebrity'. Celebrity Studies 2 (3): 292-304. doi.org/10.1080/19392397.2011.609335

Cloonan, M. 2009. 'The Production of English Rock and Roll Stardom in the 1950s'. Popular Music History 4 (3): 271-287.

Csikszentmihalyi, M. 1988. 'Society, Culture, and Person: A Systems View of Creativity'. In Conception of Giftedness, edited by R. J. Sternberg and J. Davidson, 325-339. New York: Cambridge University Press.

Deller, R. A. 2016. 'Star Image, Celebrity Reality Television and the Fame Cycle'. Celebrity Studies 7 (3): 373-389. doi.org/10.1080/19392397. 2015.1133313

Duffett, M. 2009. “We Are Interrupted by Your Noise": Heckling and the Symbolic Economy of Popular Music Stardom'. Popular Music and Society 32 (1): 37-57. doi.org/10.1080/03007760802207734

Dyer, R. 1998. Stars. New edition, with a supplementary chapter and bibliography by Paul McDonald. London: British Film Institute. Original edition, 1979.

—. 2004. Heavenly Bodies: Film Stars and Society. 2nd ed. Abingdon: Routledge.

Geraghty, C. 2000. 'Re-examining Stardom: Questions of Texts, Bodies and Performance'. In Reinventing Film Studies, edited by C. Gledhill and L. Williams, 183-202. London: Arnold. 
Gledhill, C (ed.). 1991. Stardom: Industry of Desire. London: Routledge. doi.org/10.4324/9780203400425

Goehr, L. 2007. The Imaginary Museum of Musical Works: An Essay in the Philosophy of Music. Oxford: Oxford University Press.

Grohl, D., J. A. Rota and J. Ramsay. 2013. Sound City. Roswell Films Ltd.

Holmes, S. 2004. “'Reality Goes Pop!”: Reality TV, Popular Music and Narratives of Stardom in Pop Idol'. Television and New Media 5 (2): 147-172. doi.org/10.1177/1527476403255833

Inglis, F. 2010. A Short History of Celebrity. Princeton: Princeton University Press. doi.org/10.1515/9781400834396

Inglis, I. 1996. 'Ideology, Trajectory and Stardom: Elvis Presley and the Beatles'. International Review of the Aesthetics and Sociology of Music 27 (1): 53-78. doi.org/10.2307/3108371

Jermyn, D. 2012. “'Get a Life, Ladies. Your Old One is Not Coming Back": Ageing, Ageism and the Lifespan of Female Celebrity'. Celebrity Studies 3 (1): 1-12. doi.org/10.1080/19392397.2012.644708

Keightley, K. 2001. 'Reconsidering Rock'. In The Cambridge Companion to Pop and Rock, edited by S. Frith, W. Straw and J. Street, 109142. Cambridge: Cambridge University Press. doi.org/10.1017/ CCOL9780521553698.008

Marshall, P. D. 1997. Celebrity and Power: Fame in Contemporary Culture. Minneapolis: University of Minnesota Press.

McNally, K. 2008. When Frankie Went to Hollywood: Frank Sinatra and American Male Identity. Urbana: University of Illinois Press.

Moore, A. F. 2002. 'Authenticity as Authentication'. Popular Music 21 (2): 209-223. doi.org/10.1017/S0261143002002131

Orgeron, M. 2008. 'Media Celebrity in the Age of the Image'. In The Oxford Handbook of Film and Media Studies, edited by R. Kolker, 187-223. Oxford: Oxford University Press. doi.org/10.1093/ oxfordhb/9780195175967.013.0007

Oxford English Dictionary Online. 2016. Oxford University Press. oed.com 
Redmond, S. 2010. 'Avatar Obama in the Age of Liquid Celebrity'. Celebrity Studies 1 (1): 81-95. doi.org/10.1080/19392390903519081

Redmond, S. and S. Holmes. 2007. 'Introduction: What's in a Reader?' In Stardom and Celebrity: A Reader, edited by S. Redmond and S. Holmes, 1-12. London: SAGE. doi.org/10.4135/9781446269534.n1

Rhys, S. 2013. 'Ian Watkins: Standing by Him Could Help Heal "A Very Broken Family" Says Stepdad'. Wales Online, 19 December. walesonline.co.uk/news/wales-news/ian-watkins-standing-himcould-6429786 (accessed March 2017).

Rosen, S. 1981. 'The Economics of Superstars'. American Economic Review 71: 845-858.

Shuker, R. 2012. Popular Music Culture: The Key Concepts. Abingdon and New York: Routledge.

—. 2016. Understanding Popular Music Culture. London: Routledge.

Shumway, D. R. 2007. 'Authenticity: Modernity, Stardom, and Rock \& Roll'. Modernism/Modernity 14 (3): 527-533. doi.org/10.1353/ $\bmod .2007 .0076$

Strong, C. and B. Lebrun. 2015. Death and the Rock Star. London: Routledge.

Toynbee, J. 2000. Making Popular Music: Musicians, Creativity and Institutions. London: Oxford University Press.

Turner, G. 2014. Understanding Celebrity. 2nd ed. London: SAGE. doi. org/10.4135/9781473957855

Turner, G., F. Bonner and P. D. Marshall. 2000. Fame Games: The Production of Celebrity in Australia. Cambridge: Cambridge University Press.

Warwick, J. 2012. “You Can't Win, Child, but You Can't Get Out of the Game": Michael Jackson's Transition from Child Star to Superstar'. Popular Music and Society 35 (2): 241-249. doi.org/ 10.1080/03007766.2011.618052

Wyn Jones, C. 2008. The Rock Canon: Canonical Values in the Reception of Rock. Aldershot: Ashgate. 
This text is taken from Popular Music, Stars and Stardom, edited by Stephen Loy, Julie Rickwood and Samantha Bennett, published 2018 by ANU Press, The Australian National University, Canberra, Australia.

doi.org/10.22459/PMSS.06.2018.01 